\title{
Verification and application of bird strike analysis for the design of high-speed helicopter composite cowlings
}

\author{
Radek Doubrava ${ }^{1, *}$, Martin Oberthor ${ }^{1}$, Petr Bělský ${ }^{1}$, and Bohuslav Cabrnoch ${ }^{1}$ \\ ${ }^{1}$ VZLÚ - Czech Aerospace Research Centre, Beranových 130, Prague 9, 199 05, Czech Republic
}

\begin{abstract}
Bird strikes are an important phenomenon that must be taken into consideration when designing aircraft. A bird impact experiment provides a direct method to examine the bird strike resistance. However, the design of the aircraft structures usually involves many iterations of designmanufacturing-test and conducting bird impact experiments is not only time consuming but also costly. The aim of this work is to show the application of test verified numerical simulation for the design of composite cowlings of the high-speed helicopter.
\end{abstract}

\section{Introduction}

Foreign object damage (FOD) such as bird, hail, debris etc. are important phenomena that must be taken into consideration when designing aircraft. The critical parts of planes or helicopters are windshield, nose, fuselage panels, wing and empennage leading edges, rotor blades, fan blades, engines cowlings and inlets [1].

International certification regulations require that all forward-facing aircraft components should be proven to withstand bird strikes to a certain level before they can be employed in an aircraft [2]. A bird impact test provides a direct method for determining bird strike resistance; however, the design of aircraft structures typically involves many iterations from design to manufacturing to testing and back, requiring that many bird impact tests to be conducted. This is not only time consuming, but also costly. Furthermore, experimental data from these tests are often narrowly focused, constituting a barrier for their direct use in refining structural design. Owing to these shortcomings, several numerical methods have been developed to simulate bird strikes to reduce the number of intermediate tests required and subsequently shorten the duration of the component design phase [3].

The testing program was established to assist in the selection of a composite material and optimised lay-up from the point of view of energy absorption from bird and hail impacts on the composite cowlings of new high-speed helicopter. The tests and analysis were initiated using low impact energy tests on small test specimens according to the procedures given in ASTM D7136M [5] and can be expanded to high-speed impact tests on flat test specimens to verify the manufacture and performance of a complexly shaped part. The flat and simple curved test specimen used in the high-speed impact resistance verification tests was designed

\footnotetext{
*Corresponding author: doubrava@,vzlu.cz
} 
to provide confirmation of the performance of the selected composite material and to assist in the finite element modelling of the global structure [6]. All numerical models were calibrated based on experimental results gathered with an visual observation toward damage initiation and propagation behaviours. Figure 1 shows building block diagram for the proposed approach.

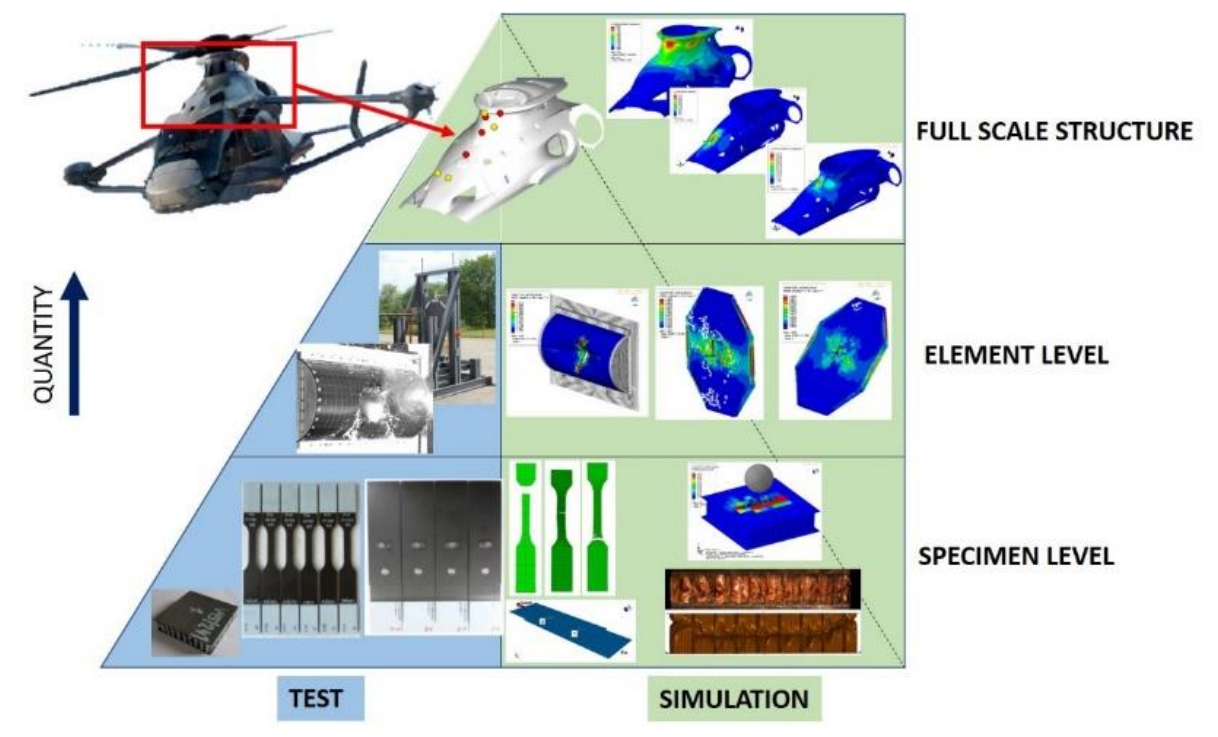

Fig. 1. Building block diagram for bird strike resistance analysis of composite cowlings.

\section{Materials and methods}

Impact tests were performed at the Czech Aerospace Research Centre (VZLÚ). The required impact velocity was achieved using a properly pressurized air gun-type pressure vessel. The projectiles were accelerated by compressed air through the smooth borehole of a gun barrel up to the required velocity according to specifications. Figure 2 shows the air gun test facilities.

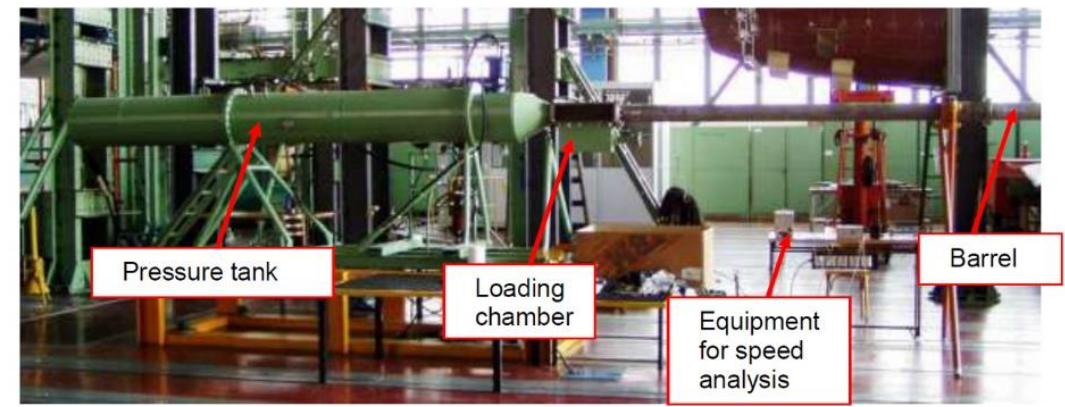

Fig. 2. VZLU air gun for bird strike tests

A flat and curved test specimen was attached to the VZLU test rigs (see figure 3). Test rigs were designed to allow the same boundary condition using for numerical simulation and measurement during the impact test (high-speed camera, load cells, etc.). 

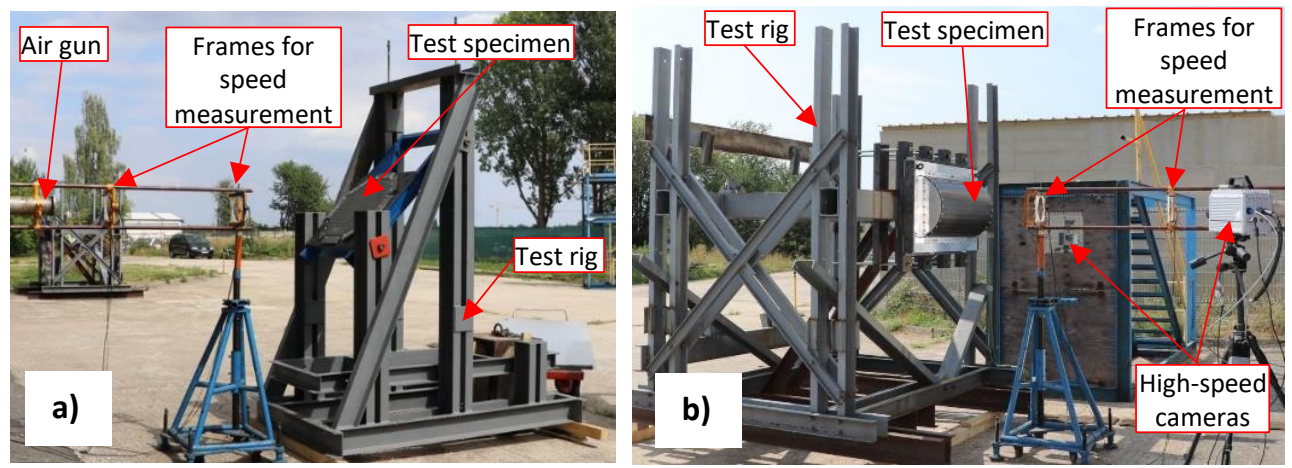

Fig. 3. VZLU test rigs to attached of flat (a) and curved (b) test specimen for bird strike tests

Test plan of flat/curved panels was defined in dependency on the preliminary design of the final part, bird mass and impact speed range. The flat test specimens represented monolithic and sandwich structure design (figure 4). The different attachment design of the flat test specimens was proposed for ensuring the same boundary condition with the numerical model.
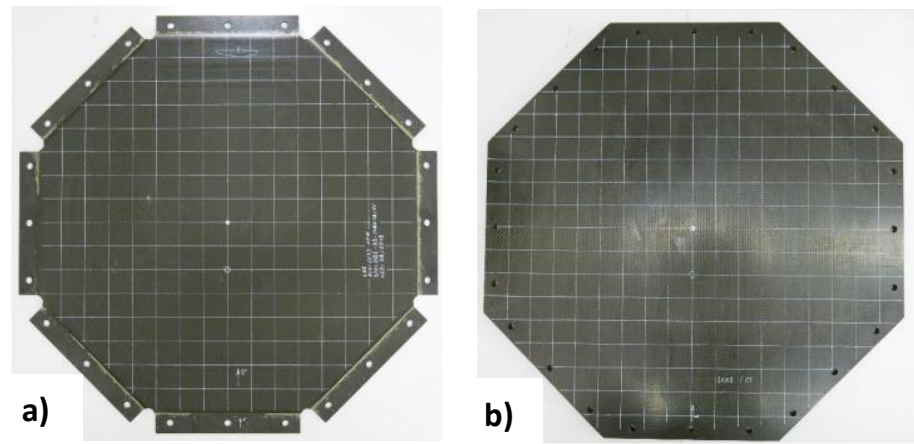

Fig. 4. Flat test specimen (a-monolithic; b- sandwich)

The curved test specimens represented sandwich structure design. The simple curved test specimen was instal to the metallic frame (figure 5). The ends of curved test specimen were supported by metallic ribs. 


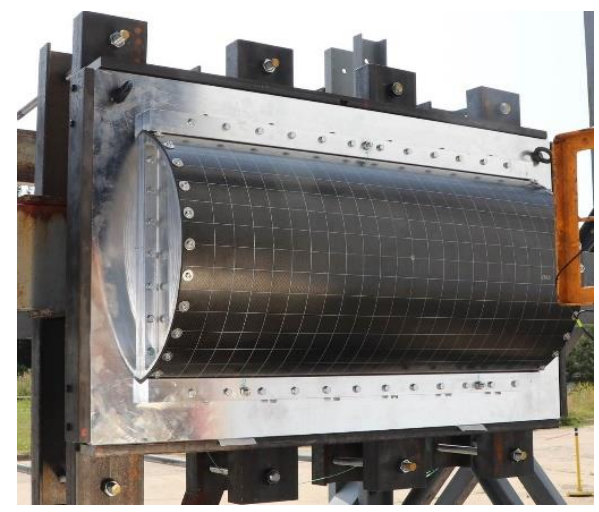

Fig. 5. Curved test specimen with metallic frame and end ribs.

For flat test specimen it was realised 12 bird strike tests ( 6 for perpendicular impact and 6 for declined impact $45^{\circ}$ ). For curved test specimens it was realised 3 bird strike tests.

The range of test speed was 375 to $586 \mathrm{~km} / \mathrm{h}$ for flat test specimens and from 326 to 450 $\mathrm{km} / \mathrm{h}$ for curved test specimen. The speed of impact was defined on the result of the previous test. The main criterion was visible damage. The change of speed was about $10 \%$.

Instrumentation of bird strike tests included high speed cameras measurement, high speed load cells for reaction forces measurement and projectile speed measurement based on the principle of time measurement which the projectile needs for transit of selected distance.

Visual and ultrasonic non-destructive inspections of all specimens were performed before and after bird strike tests. Monolithic panels and skins of flat sandwich panels were inspected by immersion C-scan Pulse-Echo method.

\section{Numerical simulation}

The FE simulations were performed using the ABAQUS FE software package [7]. An explicit solver with double precision was used for the analyses. The general contact of ABAQUS/Explicit was used for contact analysis between all parts of the FE model during impact analysis.

The particle elements (SPH - Smoothed Particle Hydrodynamics) with the hydrodynamic material model was used for bird projectile simulation. Two geometry type of projectile (sphere and cylinder with spherical ends) was used for analysis (see figure 6) from point of view of different impact energy distribution.

a)

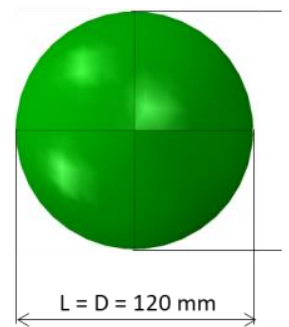

b)

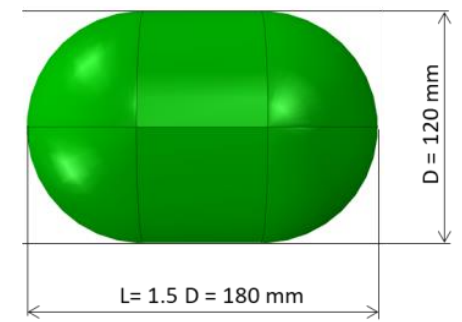

Fig. 6. Geometry of projectiles used for numerical simulation $(a-$ sphere; $b$ - cylinder with spherical ends) 
From the point of view of the damage analysis of a composite material, the Hashin's damage material model was used. The expressions for the Hashin tensile fibre failure criteria [8], after some bi-dimensional simplifications $\left(\sigma_{3}=\tau_{13}=0\right)$, are shown below in equations (1) and (2). Damage initiation occurs when either of these indices exceeds 1.

$$
\begin{array}{ll}
\left(\frac{\sigma_{1}}{\sigma_{1 u}^{t}}\right)^{2}+\left(\frac{\tau_{12}}{\tau_{12 u}}\right)^{2}=1 & \left(\sigma_{1}>0\right) \\
\left(\frac{\sigma_{2}}{\sigma_{2 u}^{t}}\right)^{2}+\left(\frac{\tau_{12}}{\tau_{12 u}}\right)^{2}=1 & \left(\sigma_{2}>0\right)
\end{array}
$$

where $\sigma_{1}$ is the stress in direction $1 ; \sigma_{\mathrm{t} 1 u}$ is the ultimate tensile stress in direction 1 (maximum tensile longitudinal strength); $\sigma_{2}$ is the stress in direction 2; $\sigma_{\mathrm{t} 2} u$ is the ultimate tensile stress in direction 2 (maximum tensile transversal strength); $\sigma_{3}$ is the stress in direction 3 ; $\tau_{13}$ is the shear stress in plane $1-3 ; \tau_{12}$ is the shear stress in plane $1-2$; and $\tau_{12 u}$ is the ultimate shear stress in plane 1-2 (maximum shear strength in plane 1-2).

\section{Verification of numerical simulation}

The test results are compared to numerical simulations and the correlation of the models is performed. Altered parameters for material properties calibration on the base of test results were porosity of the projectile, fracture energy of composite material and hardness parameters of crushable foam material model of sandwich core. The input parameters for calibration from the test results were maximal displacement during impact, reaction forces and results from non-destructive inspections (NDI).

The figure 7 shows example of analysis of maximal displacement during the impact.

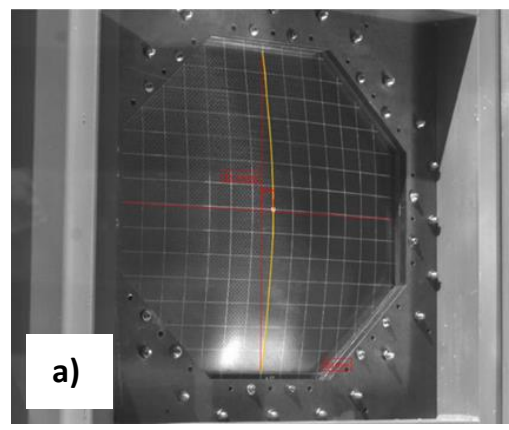

b)

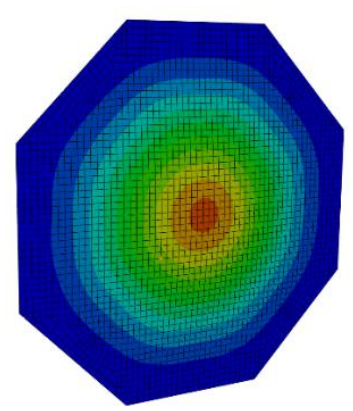

Fig. 7. Analysis of maximal displacement from high-speed camera (a) and result of numerical simulation (b). The red lines (a) shows undeformed shape and yellow line maximal deformed shape.

The figure 8 shows comparison between result of NDI and numerical simulation (red colour show damage area). The some differences in the direct comparison of the experiment with numerical simulation stem mainly from the different concentrations of the mass of the real projectile - bird (tissue, bones etc.) during the impact with an ideal numerical model. 

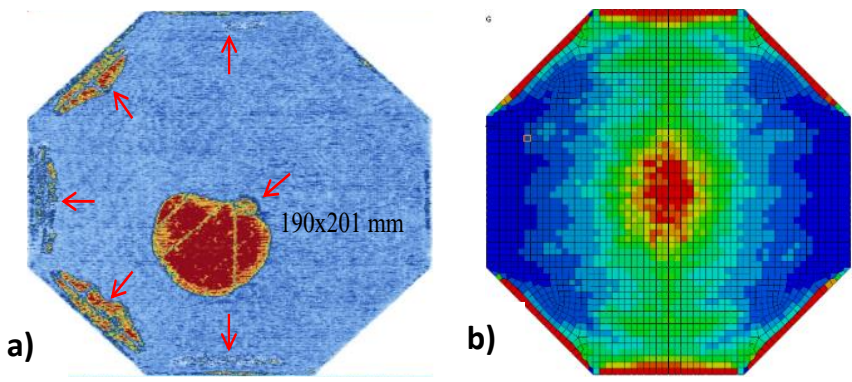

Fig. 8. Comparison between NDI (a) result and numerical simulation (b) of flat test panel.

Curved specimens were inspected manually by A-scan method. The figure 9 shows comparison between test result and numerical simulation from point of view of damage sandwich core.
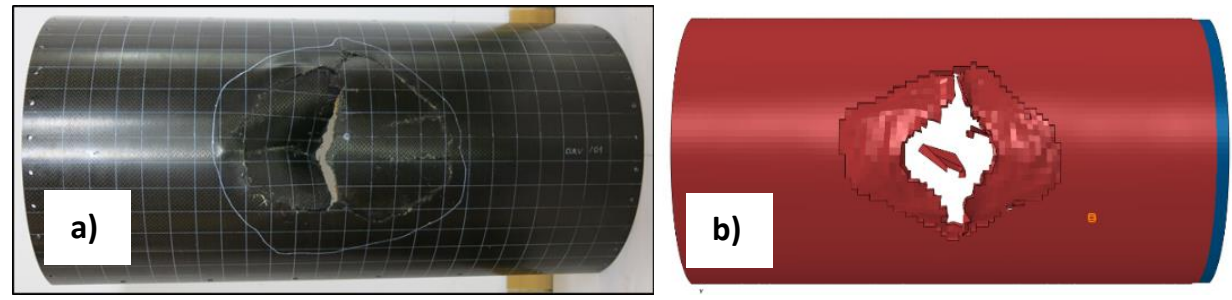

Fig. 9. Comparison between NDI result and numerical simulation of curved test specimen.

\section{Application on real structure}

The analyses of full-scale composite cowlings were performed according to CS29.631 airworthiness requirements [9] for cruise speed and bird mass $1 \mathrm{~kg}$. The design of composite cowlings and integrated part of a structure such as frames, antennas, fasteners were analysed for 11 bird trajectories and two lengths of the bird projectiles (figure $10 \mathrm{~b}$ ).

The global FE model (figure 10 a) used the same parameters as used for verification and calibration of FE models of flat and curved panels such us size and quality of element, properties etc.
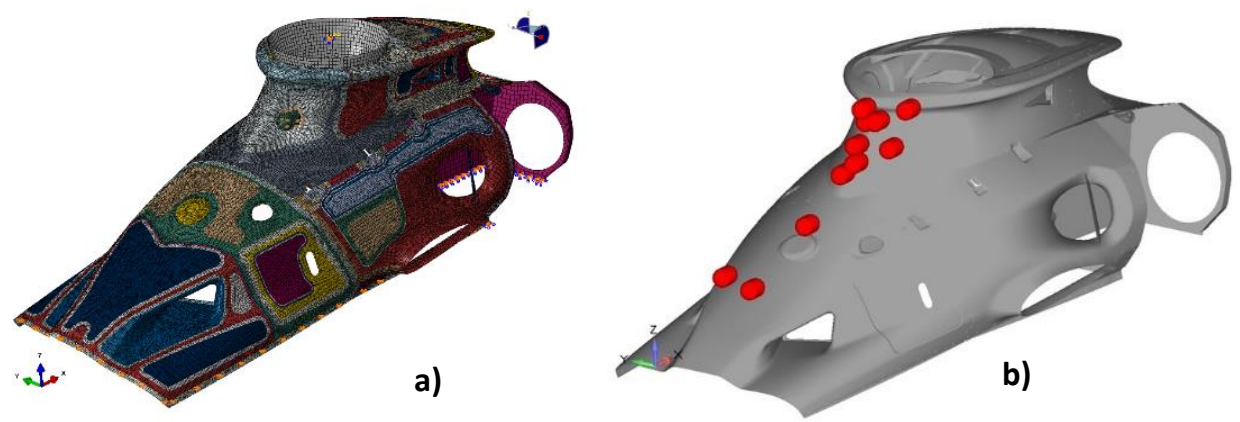

Fig. 10. Global FE model of cowlings (a) and trajectory of bird projectile (b). The colour in figure (a) shows different section properties. 
The analyses parameters for each trajectory were displacement, contact with inner parts mainly in rotor area, composite damage criterion (tensile fibre), sandwich core damage, a load of fasteners and weight of penetrated parts of the projectile in case of cowling failure.

The figure 11 shows example of one of the 11 bird impact trajectories and results from numerical simulation for analysis of contact with rotated or inner parts and damage analysis of composite structure. The results for this trajectory impact confirm the resistance of the proposed design from point of view of no failure of the structure or threat of rotor.

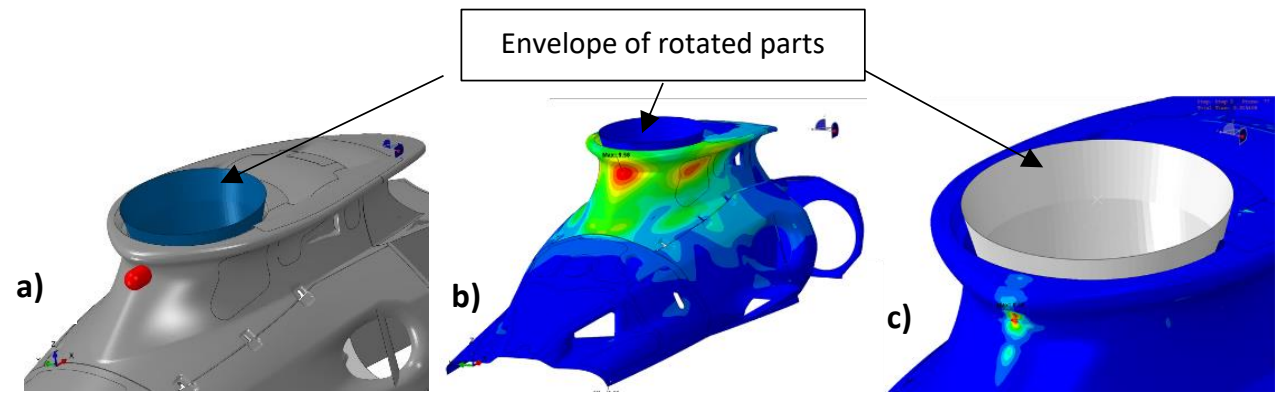

Fig. 11. Example of bird strike analysis of impact near the rotated parts ( a) - trajectory of projectile; b) - contour map of displacement; c) - contour map of composite damage criterion)

\section{Conclusion}

The application of validated numerical models on the flat and simply curved test specimen enabled improvements and optimization in the design phase. The experiences obtained in the field of calibration of numerical models for high-speed impacts confirm different behaviour of isotropic and orthotropic material models. The application of verified numerical models in the field of emergency load cases using simple test specimens allows not only the optimization of the design in terms of compliance with airworthiness regulations, but also increasing the durability and safety of newly designed composite structures.

This project has received funding from the Clean Sky 2 Joint Undertaking under the European Union's Horizon 2020 research and innovation programme under grant agreement No 737955.
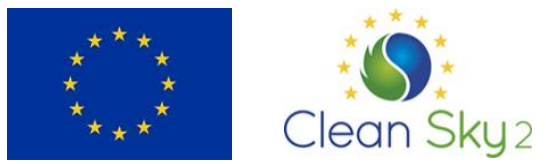

\section{References}

1. R. Hedayati, M. Sadighi, Woodhead Publishing, ISBN: 978-0-08-100093-9, Elsevier (2015)

2. R. Batra, et al., Composite structures, 94 (2012)

3. S. Sánchez-Sáez, E. Barbero, C. Composites Science and Technology, vol. 67(11), pp. 2616-2632, (2007)

4. S. Heimbs, Computers \& Structures, Vol. 89(23) pp. 2093-2112 (2011)

5. ASTM D7136M - 07 
6. R. Doubrava, M. Oberthor, P. Bělský, J. Raška, International Journal of Structural Integrity, Emerald Publishing Limited, 1757-9864, DOI 10.1108/IJSI-10-2018-0059 (2019)

7. ABAQUS 6.14

8. Z. Hashin, ASME Journal of Applied Mechanics, Vol. 47, pp. 329-334 (1981)

9. EASA, CS29.631 